\title{
Renal Effects of Calcitonin and Parathyroid Extract in Man
}

\author{
STUDIES IN HYPOPARATHYROIDISM
}

\author{
Heinrich G. HaAs, Maximuian A. Dambacher, Jan Gunčaga, and \\ THIERRY LAUFFENBURGER \\ From the Division of Endocrinology and Metabolism, Department of \\ Medicine, University Hospital (Bürgerspital), CH 4000 Basel, Switzerland
}

A B S T R A C T To clarify the controversial renal action of calcitonin (CT) and a possible interrelationship between CT and parathyroid hormone, eight patients with untreated surgical hypoparathyroidism were studied. Various calcitonins, i.e. extracted porcine, synthetic porcine, synthetic human, and synthetic salmon CT in doses of 150 Medical Research Council U or $1.5 \mathrm{mg}$ were infused over a $3 \mathrm{hr}$ period. Subsequently, six of the same subjects received 500 USP U parathyroid extract (PTE) (Eli Lilly \& Co., Indianapolis, Ind.) in $3 \mathrm{hr}$ and later a combination of CT and PTE. In addition, two patients were given an infusion of ammonium phosphate with the aim of producting a phosphaturia of comparable degree as seen after CT and PTE, thus differentiating hormonal from nonhormonal influences on cation excretion. A protocol of serial clearance (C) studies using the patients as their own controls was followed. Serum and urinary inorganic phosphate $(\mathrm{P})$, calcium $(\mathrm{Ca})$, magnesium $(\mathrm{Mg})$, sodium $(\mathrm{Na})$, potassium $(\mathrm{K})$, and creatinine $(\mathrm{Cr})$ were determined and the clearance values calculated.

All CT peptides caused a uniform, immediate and significant increase of $\mathrm{C}_{\mathrm{P}}, \mathrm{C}_{\mathrm{Na}_{\mathrm{a}}}, \mathrm{C}_{\mathrm{K}}, \mathrm{C}_{\mathrm{Ca}}$, and $\mathrm{C}_{\mathrm{Mg}}$. PTE evoked a rise of $\mathrm{C}_{\mathrm{P}}, \mathrm{C}_{\mathrm{Na}}$, and $\mathrm{C}_{\mathrm{K}}$, but $\mathrm{C}_{\mathrm{Ca}}$ and $\mathrm{C}_{\mathrm{Mg}}$ were reduced, the $\mathrm{Ca}$ and $\mathrm{Na}$ figures being not statistically significant. The administration of both $\mathrm{CT}$ and PTE resulted in a summation of individual hormone effects on $\mathrm{Ca}$ and $\mathrm{Mg}$ excretion. Phosphate infusion on the other hand induced an isolated phosphaturia but no concomitant changes of the urinary cations.

This work was presented in part at the 15 th Symposium of the German Society for Endocrinology, 3 March 1969, Cologne, Germany, and in part at the annual meeting of the Swiss Endocrine Society, 25 October 1969, in Berne, Switzerland.

Received for publication 9 September 1970 and in revised form 24 June 1971.
The hypoparathyroid data demonstrate that calcitonin enhances urinary elimination of $\mathrm{P}, \mathrm{Na}, \mathrm{K}, \mathrm{Ca}$, and $\mathrm{Mg}$ independently of parathyroid action. CT and PTE act qualitatively similarly on $\mathrm{P}, \mathrm{Na}$, and $\mathrm{K}$ excretion, while an antagonism seems to exist for the renal handling of $\mathrm{Ca}$ and $\mathrm{Mg}$.

\section{INTRODUCTION}

Numerous studies have conclusively shown that CT acts on bone, but its kidney action is still far from clear (1). Kenny and Heiskell (2) first demonstrated a phosphaturic effect in parathyroidectomized (PTX) ${ }^{1}$ rats which was later confirmed by several groups of investigators (3-6). This effect is also obtained in dogs provided that the parathyroids are left intact $(7,8)$. In the pig, only very large doses of CT provoke phosphaturia (9) and no consistent results are obtained after $\operatorname{PTX}(6,9)$. Phosphaturia in man was detected by Bijvoet, Van der Sluys Veer, and Jansen (10) and their findings were subsequently confirmed by two groups of investigators (11, 12). However, in all these patients secondary parathyroid stimulation may have accounted for the observed increase of phosphate excretion (UP). So far only Ardaillou, Fillastre, Milhaud, Rousselet, Delaunay, and Richet (13) were able to produce a significant phosphaturia in one patient with hypoparathyroidism by infusing porcine CT, $3.2 \mathrm{MRC} \mathrm{U} / 8 \mathrm{hr}$. At the same time, these authors observed a transient increase of urinary calcium (UCa), sodium ( $\mathrm{UNa}$ ), and chloride while no consistent changes of urinary magnesium (UMg) and potassium

${ }^{1}$ Abbreviations used in this paper: $\mathrm{C}$, clearance; $\mathrm{Cr}$, creatinine; CT, calcitonin; DHT, dihydrotachysterol; ECF, extracellular fluid; GFR, glomerular filtration rate; MRC, Medical Research Council; PTE, parathyroid extract; PTH, parathyroid hormone; PTX, parathyroidectomized; $\mathrm{U}$, urinary. 
TABLE I

Patients and Base Line Values

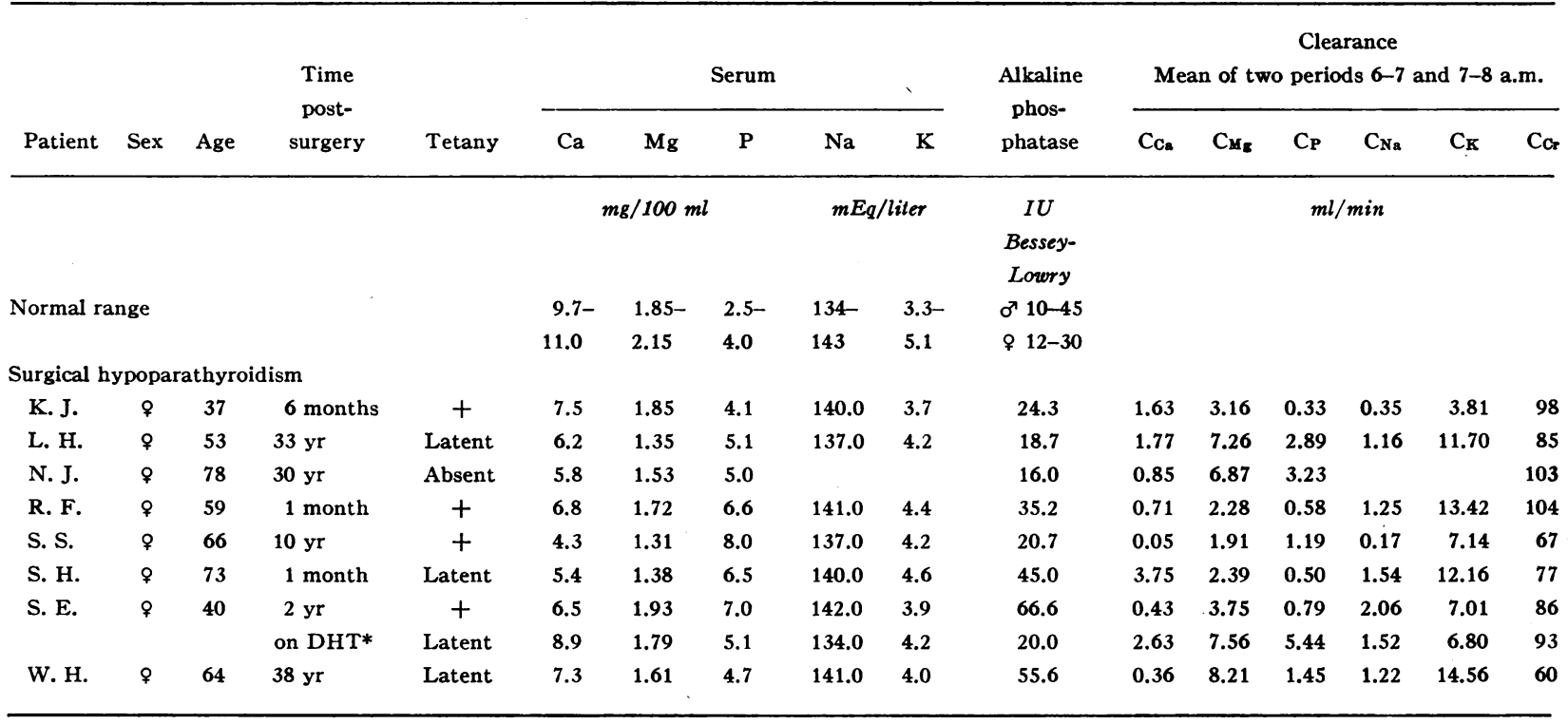

* Dihydrotachysterol $1.33 \mathrm{mg} /$ day (second admission).

(UK) were seen. Similar effects on UCa and UNa were detected by several investigators $(4,10,11)$, but interferences by parathyroid hormone $(\mathrm{PTH})$ were not ruled out. Since the hypoparathyroid patient of Ardaillou et al. (13) had been on a maintenance dose of vitamin $\mathrm{D}$ and since all their subjects were given only minute doses of extracted porcine $\mathrm{CT}$, there remain doubts about the significance of the reported renal effects.

The present investigation, part of which was presented in preliminary form $(14,15)$, was designed to clarify the controversy whether CT exerts a direct influence on the kidney or secondary parathyroid stimulation is responsible for the apparent renal effects. In view of this, patients with untreated surgical hypoparathyroidism received alternately CT and PTE in order to further delineate the relative importance of these factors in regulating $\mathrm{Ca}, \mathrm{Mg}, \mathrm{Na}, \mathrm{K}$, and $\mathrm{P}$ excretion. In addition, the present study aimed at excluding a secondary, nonhormonal influence of induced phosphaturia on the renal handling of cations as discussed by Eisenberg (16). It was shown that CT and PTE in pharmacologic doses act independently on the human kidney, both hormones promoting $\mathrm{P}, \mathrm{Na}$, and $\mathrm{K}$ excretion while $\mathrm{CT}$ alone increases $\mathrm{C}_{\mathrm{Ca}}$ and $\mathrm{C}_{\mathrm{Ar}}$, thus antagonizing PTE. These findings may have physiological implications regarding $\mathrm{Ca}$ and $\mathrm{P}$ homeostasis.

\section{METHODS}

Eight women with untreated surgical hypoparathyroidism were studied. Four showed episodes of frank tetany. In three, it was classified as "latent" as only Trousseau's sign was positive. In one case no tetanic symptoms could be evoked. Initial $\mathrm{Ca}$ values ranged from 4.3 to $7.5 \mathrm{mg} / 100 \mathrm{ml}$ and inorganic $\mathrm{P}$ from 4.1 to $8.0 \mathrm{mg} / 100 \mathrm{ml}$ (Table I). Na and $K$ levels were within normal range while three patients showed a slight, and one a distinct, elevation of alkaline phosphatase in the absence of liver disease. This finding was interpreted to point to an osteomalacic component, such as seen in PTX dogs (17), rather than to an increased bone turnover. In none of the subjects was renal function seriously impaired. However, during hospitalization, patient S.S. experienced a flare-up of her chronic pyelonephritis and studies had to be stopped before completion of the protocol. In addition, because of technical difficulties with serial venepuncture, repeated catheterization, or occasional loss of specimens, complete studies were not possible in all subjects. When patient S. E. was studied for the second time, she had been on treatment with dihydrotachysterol (DHT) for several months, but for unknown reasons had relapsed into a state of latent hypocalcemic tetany subsequent to a cataract operation.

\section{General conditions, timing of collections, and drug administration}

A protocol of paired clearance studies lasting from 6 a.m. to 1 p.m. was followed. All subjects were given a regular hospital diet but studies were done in the fasting state. Between experimental days, an interval of at least 1 day was observed. On experimental days, a constant urine flow was 
TABLE II

Changes of Phosphate Excretion $\left(\Delta C_{P} / C_{C_{r}} \mathrm{ml} / \mathrm{min}\right)$ (including Serum-P $[\mathrm{mg} / 100 \mathrm{ml}]$ and $\left.C_{C_{r}}[\mathrm{ml} / \mathrm{min}]\right)$

\begin{tabular}{|c|c|c|c|c|c|}
\hline \multirow[b]{2}{*}{ Time } & \multicolumn{3}{|c|}{ Hormone infusion } & \multirow[b]{2}{*}{11 a.m. -12 nown } & \multirow[b]{2}{*}{12 noon-1 p.m. } \\
\hline & 8-9 a.m. & 9-10 a.m. & 10-11 a.m. & & \\
\hline $\begin{array}{l}\text { Control } \\
\quad \text { Mean } \Delta \mathrm{C}_{\mathbf{P}} \\
\pm \mathrm{SE}\end{array}$ & $\begin{array}{l}+0.27 \\
\pm 0.34\end{array}$ & $\begin{array}{l}+0.22 \\
\pm 0.22\end{array}$ & $\begin{array}{l}+0.29 \\
\pm 0.16\end{array}$ & $\begin{array}{l}-0.19 \\
\pm 0.39\end{array}$ & $\begin{array}{l}+0.02 \\
\pm 0.52\end{array}$ \\
\hline $\begin{array}{l}\text { Mean serum-P } \\
\pm \text { SE }\end{array}$ & $\begin{array}{r}5.01 \\
\pm 0.33\end{array}$ & $\begin{array}{r}5.05 \\
\pm 0.32\end{array}$ & $\begin{array}{r}5.05 \\
\pm 0.34\end{array}$ & $\begin{array}{r}5.03 \\
\pm 0.38\end{array}$ & $\begin{array}{r}5.12 \\
\pm 0.39\end{array}$ \\
\hline $\begin{array}{l}\text { Mean } \Delta \mathrm{C}_{\mathrm{Cr}} \\
\pm \mathrm{SE}\end{array}$ & $\begin{array}{r}-0.01 \\
\pm 11.90\end{array}$ & $\begin{array}{l}+7.01 \\
\pm 6.16\end{array}$ & $\begin{array}{l}-3.74 \\
\pm 7.50\end{array}$ & $\begin{array}{l}-2.14 \\
+6.73\end{array}$ & $\begin{array}{l}+7.12 \\
\pm 3.29\end{array}$ \\
\hline $\begin{array}{l}\text { Calcitonin }(\mathrm{CT}) \\
\text { a. CT porcine extract } \\
\text { Mean } \Delta \mathrm{C}_{\mathrm{P}} \\
\pm \mathrm{SE} \\
\quad P(\text { compared with } b, c)\end{array}$ & $\begin{array}{l}+6.58 \\
\pm 3.24\end{array}$ & $\begin{array}{l}+9.17 \\
\pm 2.81\end{array}$ & $\begin{array}{r}+10.24 \\
\pm 3.02\end{array}$ & $\begin{array}{l}+7.73 \\
\pm 2.25\end{array}$ & $\begin{array}{l}+5.98 \\
\pm 2.24\end{array}$ \\
\hline $\begin{array}{l}\text { b. CT porcine synth. } \\
\text { Mean } \Delta \mathrm{C}_{\mathbf{P}} \\
\pm \mathrm{SE} \\
\quad P \text { (compared with } a, c)\end{array}$ & $\begin{array}{l}+2.57 \\
\pm 1.24\end{array}$ & $\begin{array}{l}+5.30 \\
\pm 1.58\end{array}$ & $\begin{array}{l}+7.43 \\
\pm 1.47\end{array}$ & $\begin{array}{l}+5.40 \\
\pm 1.61\end{array}$ & $\begin{array}{l}+2.44 \\
\pm 1.16\end{array}$ \\
\hline $\begin{array}{l}\text { c. CT human synth. } \\
\text { Mean } \Delta \mathrm{C}_{\mathrm{P}} \\
\pm \mathrm{SE} \\
\quad P \text { (compared with } a, b)\end{array}$ & $\begin{array}{l}+5.69 \\
\pm 2.52\end{array}$ & $\begin{array}{r}+10.84 \\
\pm 3.28\end{array}$ & $\begin{array}{l}+8.94 \\
\pm 2.15\end{array}$ & $\begin{array}{l}+5.85 \\
\pm 1.41\end{array}$ & $\begin{array}{l}+0.70 \\
\pm 1.65\end{array}$ \\
\hline $\begin{array}{l}\text { d. CT salmon synth. } \\
\text { Mean } \Delta \mathrm{C}_{\mathrm{P}} \\
\pm \mathrm{SE}\end{array}$ & $\begin{array}{l}+7.67 \\
\pm 2.50\end{array}$ & $\begin{array}{r}+18.28 \\
\pm 3.22\end{array}$ & $\begin{array}{r}+15.12 \\
\pm 1.77\end{array}$ & $\begin{array}{r}+13.11 \\
\pm 0.24\end{array}$ & $\begin{array}{r}+10.60 \\
\pm 1.70\end{array}$ \\
\hline $\begin{array}{l}\text { e. CT all studies } \\
\text { Mean } \Delta \mathrm{C}_{P} \\
\pm \mathrm{SE} \\
\quad P \text { (compared with control) }\end{array}$ & $\begin{array}{l}+5.34 \\
\pm 1.24\end{array}$ & $\begin{array}{l}+9.84 \\
\pm 1.66\end{array}$ & $\begin{array}{l}+9.76 \\
\pm 1.24\end{array}$ & $\begin{array}{l}+7.30 \\
\pm 1.07\end{array}$ & $\begin{array}{l}+4.12 \\
\pm 1.22\end{array}$ \\
\hline $\begin{array}{l}\text { Mean serum-P } \\
\pm \mathrm{SE}\end{array}$ & $\begin{array}{r}5.86 \\
\pm 0.42\end{array}$ & $\begin{array}{r}5.68 \\
\pm 0.45\end{array}$ & $\begin{array}{r}5.57 \\
\pm 0.38\end{array}$ & $\begin{array}{r}5.50 \\
\pm 0.35\end{array}$ & $\begin{array}{r}5.31 \\
\pm 0.30\end{array}$ \\
\hline $\begin{array}{l}\text { Mean } \Delta \mathrm{C}_{\mathrm{Cr}} \\
\pm \mathrm{SE} \\
\quad P(\text { each } \Delta \text { compared with } \Delta \text { control })\end{array}$ & $\begin{array}{l}+5.56 \\
\pm 4.31 \\
\text { NS }\end{array}$ & $\begin{array}{l}-0.81 \\
\pm 4.26 \\
\text { NS }\end{array}$ & $\begin{array}{l}+2.98 \\
\pm 3.94 \\
\text { NS }\end{array}$ & $\begin{array}{l}-5.09 \\
\pm 2.63 \\
\text { NS }\end{array}$ & $\begin{array}{l}-2.14 \\
\pm 4.52 \\
\text { NS }\end{array}$ \\
\hline $\begin{array}{l}\mathrm{PTE} \\
\text { Mean } \Delta \mathrm{C}_{\mathrm{P}} \\
\pm \mathrm{SE} \\
\quad P \text { (compared with control) } \\
\quad P \text { (compared with CT) }\end{array}$ & $\begin{array}{l}+8.84 \\
\pm 1.85\end{array}$ & $\begin{array}{l}+28.18 \\
\pm 4.68\end{array}$ & $\begin{array}{l}+26.92 \\
\pm 1.50\end{array}$ & $\begin{array}{lr} & +21.42 \\
& +2.71 \\
<0.001 & \\
<0.001 & \end{array}$ & $\begin{array}{r}+11.10 \\
\pm 2.46\end{array}$ \\
\hline $\begin{array}{l}\text { Mean serum-P } \\
\pm \mathrm{SE} \\
\quad P \text { (base line value compared } \\
\quad \text { with last value) }\end{array}$ & $\begin{array}{r}6.32 \\
\pm 0.92\end{array}$ & $\begin{array}{r}5.50 \\
\pm 0.84\end{array}$ & $\begin{array}{r}5.04 \\
\pm 0.74\end{array}$ & $\begin{array}{r}4.72 \\
\pm 0.83\end{array}$ & $\begin{array}{r}4.37 \\
\pm 0.63\end{array}$ \\
\hline $\begin{array}{l}\text { Mean } \Delta \mathrm{C}_{\mathrm{Cr}} \\
\pm \mathrm{SE}\end{array}$ & $\begin{array}{l}+2.82 \\
\pm 4.89\end{array}$ & $\begin{array}{l}+1.05 \\
\pm 6.94\end{array}$ & $\begin{array}{r}-6.87 \\
\pm 10.86\end{array}$ & $\begin{array}{l}-8.35 \\
\pm 6.58\end{array}$ & $\begin{array}{l}-10.07 \\
\pm 12.44\end{array}$ \\
\hline$P($ each $\Delta$ compared with $\Delta$ control $)$ & NS & NS & NS & NS & NS \\
\hline
\end{tabular}


TABLE II-(Continued)

\begin{tabular}{|c|c|c|c|c|c|}
\hline \multirow[b]{2}{*}{ Time } & \multicolumn{3}{|c|}{ Hormone infusion } & \multirow[b]{2}{*}{11 a.m.-12 noon } & \multirow[b]{2}{*}{12 noon-1 p.m. } \\
\hline & 8-9 a.m. & 9-10 a.m. & 10-11 a.m. & & \\
\hline $\begin{array}{l}\mathrm{CT}+\mathrm{PTE} \\
\text { Mean } \Delta \mathrm{C}_{\mathrm{P}} \\
\pm \mathrm{SE}\end{array}$ & $\begin{array}{l}+9.21 \\
\pm 2.44\end{array}$ & $\begin{array}{r}+29.41 \\
\pm 3.29\end{array}$ & $\begin{array}{r}+33.98 \\
\pm 3.13\end{array}$ & $\begin{array}{r}+28.77 \\
\pm 2.76\end{array}$ & $\begin{array}{r}+19.70 \\
\pm 3.87\end{array}$ \\
\hline $\begin{array}{l}\text { Mean serum-P } \\
\pm \mathrm{SE}\end{array}$ & $\begin{array}{r}6.42 \\
\pm 0.75\end{array}$ & $\begin{array}{r}6.00 \\
\pm 0.74\end{array}$ & $\begin{array}{r}5.18 \\
\pm 0.67\end{array}$ & $\begin{array}{r}4.43 \\
\pm 0.67\end{array}$ & $\begin{array}{r}4.56 \\
\pm 0.74\end{array}$ \\
\hline $\begin{array}{l}\text { Mean } \Delta \mathrm{C}_{\mathrm{Cr}} \\
\pm \mathrm{SE}\end{array}$ & $\begin{array}{r}+13.17 \\
\pm 7.01\end{array}$ & $\begin{array}{l}-2.33 \\
\pm 6.63\end{array}$ & $\begin{array}{r}-11.30 \\
\pm 9.82\end{array}$ & $\begin{array}{r}-10.17 \\
\pm 8.49\end{array}$ & $\begin{array}{l}-0.83 \\
\pm 7.28\end{array}$ \\
\hline$P($ each $\Delta$ compared with $\Delta$ control $)$ & NS & NS & NS & NS & NS \\
\hline $\begin{array}{l}\mathrm{PO}_{4} \\
\text { Mean } \Delta \mathrm{C}_{\mathrm{P}} \\
\text { 土sE } \\
\text { Mean serum-P }\end{array}$ & $\begin{array}{r}+3.29 \\
\pm 2.71 \\
4.74\end{array}$ & $\begin{array}{r}+13.31 \\
\pm 0.18 \\
6.64\end{array}$ & $\begin{array}{r}+22.91 \\
\pm 0.09 \\
7.61\end{array}$ & $\begin{array}{r}+18.10 \\
\pm 1.84 \\
6.56\end{array}$ & $\begin{array}{r}+14.80 \\
\pm 0.72 \\
5.19\end{array}$ \\
\hline
\end{tabular}

The variation of $\mathbf{C}_{\mathbf{c}}$ is given above.

maintained by starting an infusion of $5 \%$ fructose in the preceding evening. From $2 \mathrm{hr}$ before the first urine collection until the end of the study, $250 \mathrm{ml}$ of fluid/hr were administered with an infusion pump. This was in order to avoid sudden changes of extracellular fluid volume (ECF), as rapid expansion of the extracellular space is known to interfere with the tubular reabsorptive processes (18). Since fructose is metabolized very rapidly, a $5 \%$ fructose solution was used in order to influence renal tubular ion transport as little as possible (19), and normal saline was avoided because a sodium load increases calciuria (20). Urine was collected hourly through an indwelling catheter in all subjects, and blood was drawn at 6, 7, 8, 9:30, 11 a.m., 12 noon, and 1 p.m. Venous stasis was carefully avoided.

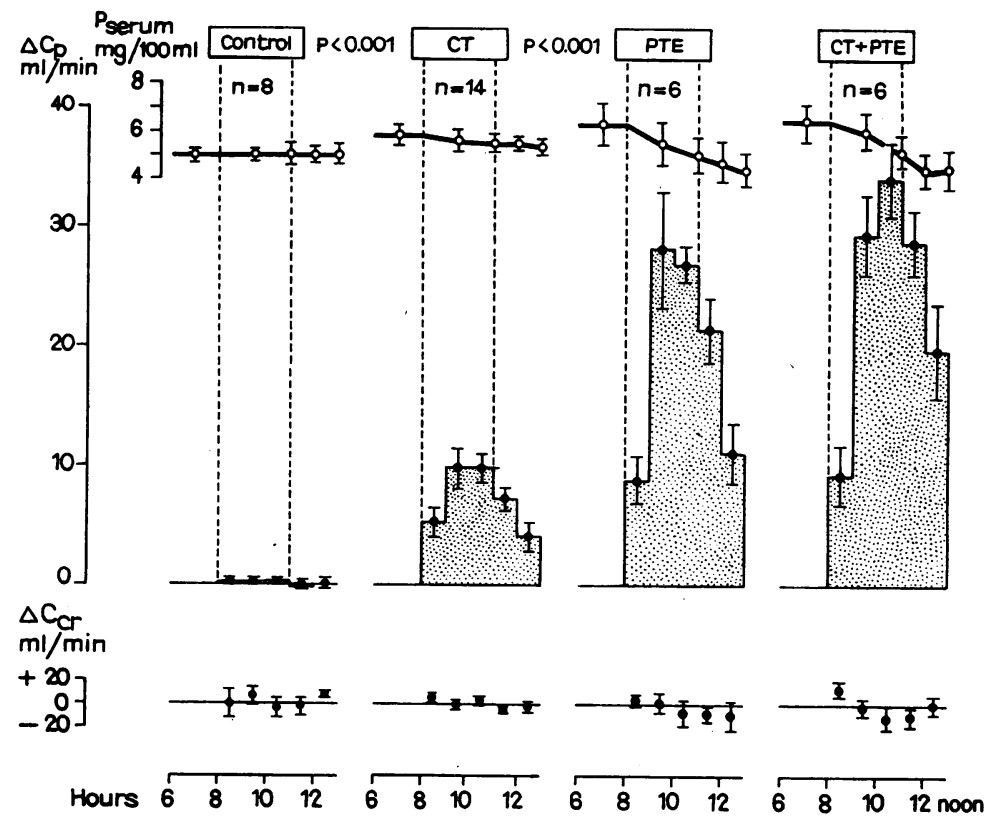

FIGURE 1 Changes in $C_{P}\left(\Delta C_{P} / C_{C_{r}}\right)$ after administration of calcitonin (pooled data from experiments with all preparations of calcitonin), parathyroid extract (PTE) and a combination of both hormones. $-0, \Delta C_{P}$ and $\Delta \mathrm{C}_{\mathrm{Cr}} \pm 1 \mathrm{SE} ; \mathrm{O}-\mathrm{O}$, serum $\mathrm{P} \pm 1 \mathrm{SE}$. Levels of statistical significance between individual hormone effects are given between columns. 


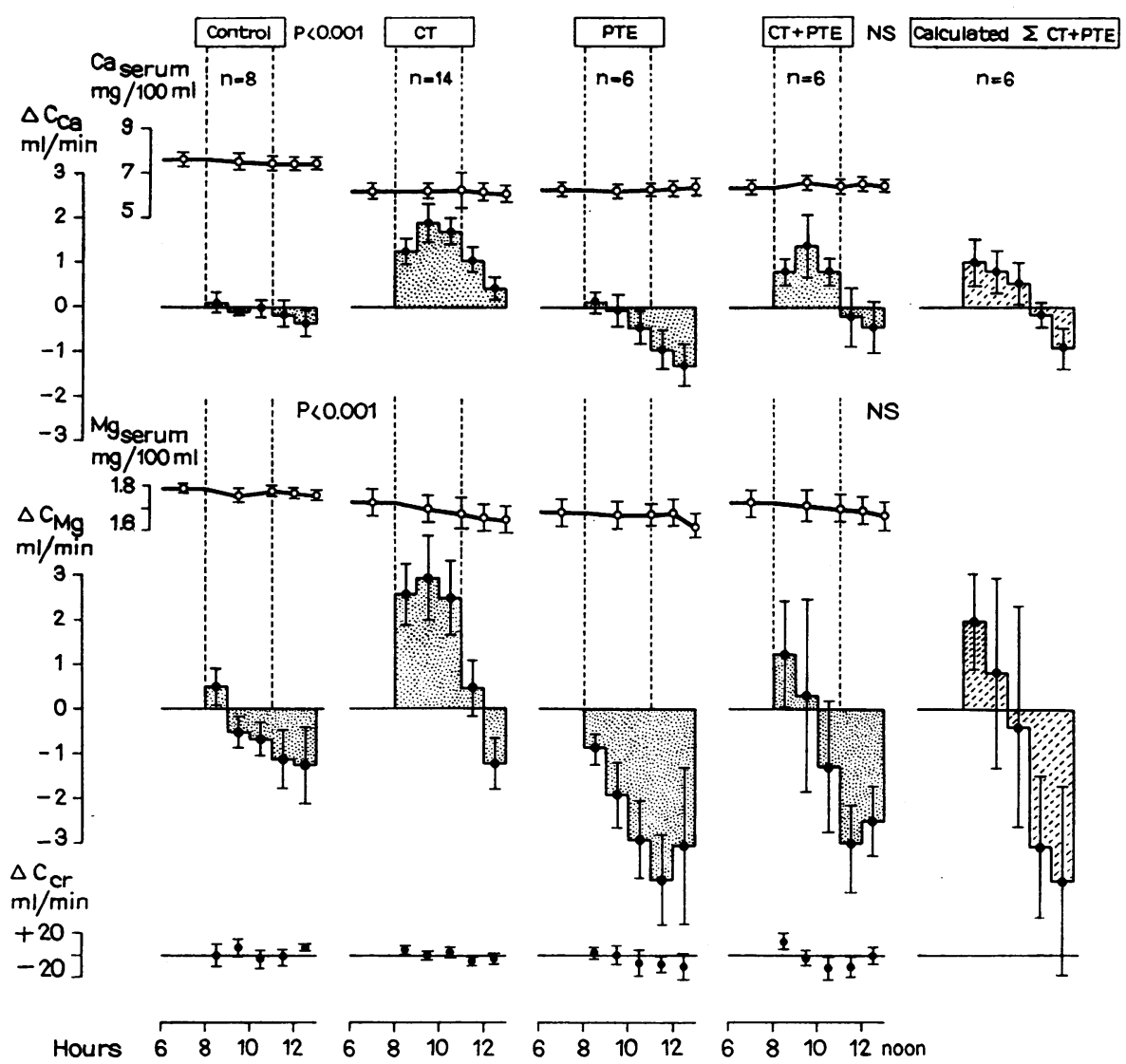

Figure 2 Top, changes of $\mathrm{C}_{\mathrm{Ca}_{2}}$ and serum $\mathrm{Ca}$. Bottom, changes of $\mathrm{C}_{\mathrm{Mg}}$ and serum $\mathrm{Mg}$. The differences in the observed changes when compared with the calculated sum of changes are not statistically significant. - - , renal clearance changes; $O-O$, serum values.

On experimental days, drugs, added to the infusion, were administered from 8 to 11 a.m. in the following order (Tables II-VI) :

Control. Eight control studies with the solvent only were performed in seven subjects, leaving out S. S. in whom investigations had to be terminated prematurely;

Extracted porcine CT. (Subjects N. I., R. F., S. H., W. H.) $150 \mathrm{MRC} U$ with a potency of approximately 50 MRC U/mg peptide (21)

Synthetic porcine CT (22). (Subjects K. J., S. S., S. H., S. E.) $1.5 \mathrm{mg}$ judged from the rat bioassay to be equivalent to $150 \mathrm{MRC} U$ (1)

Synthetic human CT (23). (Subjects K. J., L. H., S. S., S. E.) $1.5 \mathrm{mg}$

Synthetic salmon CT (24). (Subjects L .H., S. E.) 45 $\mu \mathrm{g}$, equivalent to approximately $150 \mathrm{MRC} U$ (rat bioassay)

Bovine parathyroid extract. (PTE) (Subjects N. I., R. F., S. S., S. H., S. E., W. H.) 500 USP U. This dose was judged arbitrarily to be comparable to the CT doses (25) but subsequently it was found that PTE produced a more profound phosphaturia than CT.

$A$ combination of $C T$ and PTE. (Same subjects as PTE) Depending on the availability, porcine or human CT (Table II) was given simultaneously with PTE. Since individual effects of various CT's were not significantly different (Fig. 4) pooling of the data seems justified.

Phosphate. $600 \mathrm{mg} \mathrm{P}$ as $\left(\mathrm{NH}_{4}\right)_{2} \mathrm{HPO}_{4}$ in a solution of $\mathrm{pH}$ 7.4. This salt was chosen in order to avoid an additional load of cations known to interfere with tubular $\mathrm{P}$ transport (16).

Since these studies were carried out over a period of $2 \mathrm{yr}$, not all four CT preparations could be administered to each individual. All peptides were generally well tolerated. However, some patients complained of abdominal discomfort and nausea immediately after starting the infusion, and sometimes blushing of the head was observed, but other signs of intolerance such as allergic reactions were not apparent.

\section{Methods of measurement}

Ultrafiltration of the $8,9: 30,11$ a.m., and 12 noon serum specimens was done by the Toribara method (26). Urine and serum specimens were analyzed for $\mathrm{Ca}, \mathrm{Mg}, \mathrm{Na}, \mathrm{K}$, inorganic $\mathrm{P}$, and $\mathrm{Cr}$. $\mathrm{Ca}$ and $\mathrm{Mg}$ were measured in the ultrafiltrates, too. All analyses were done in duplicate. $\mathrm{Ca}$ and $\mathrm{Mg}$ were determined by the McIntyre method (27) and $\mathrm{Na}$ and $\mathrm{K}$ by conventional flame photometry. The Fiske-Subbarow procedure (28) was used for inorganic $P$ and the Clark-Thompson 


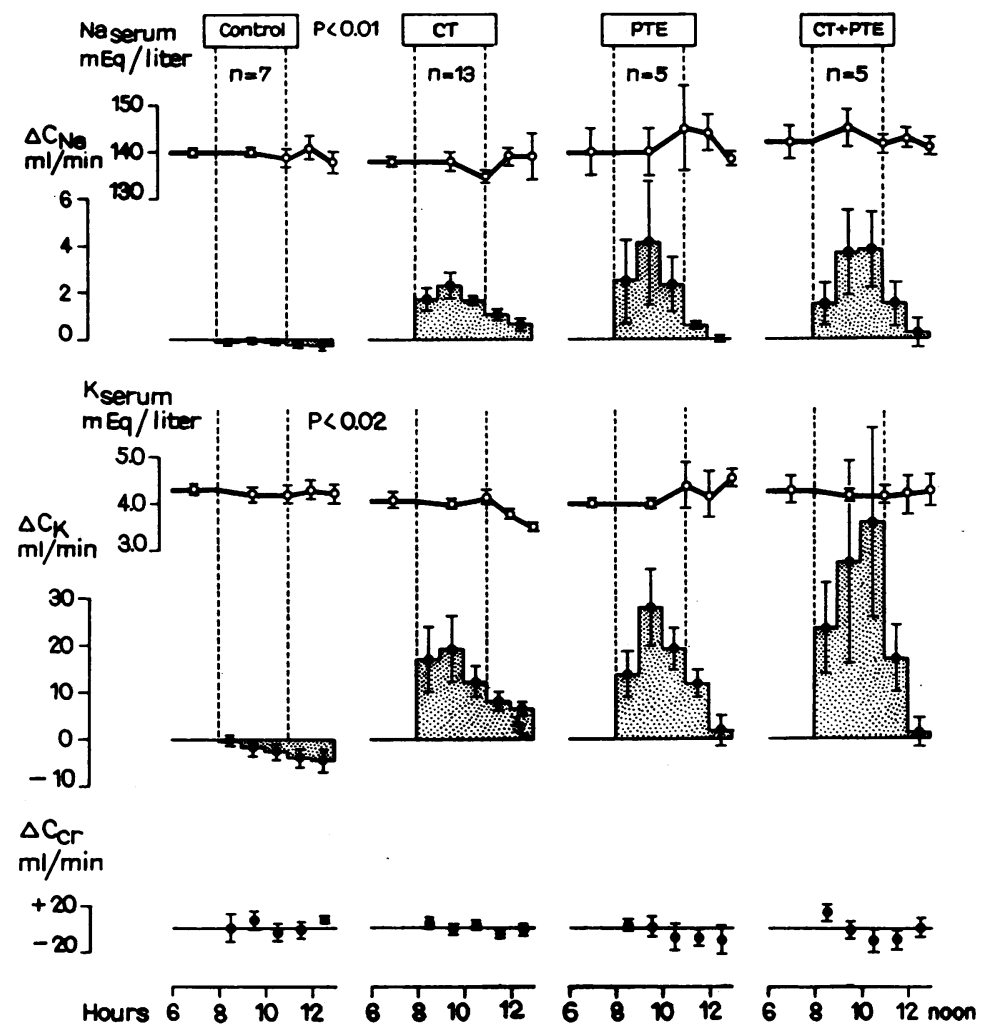

Figure 3 Changes of $\mathrm{C}_{\mathrm{Na}}$ and $\mathrm{C}_{\mathrm{K}}$. - serum values.

method (29) for creatinine. Clearances of ions were calculated, using ultrafiltrate values for $\mathrm{Ca}$ and $\mathrm{Mg}$, and each clearance figure was corrected for $\mathrm{C}_{\mathrm{c}}$.

\section{Evaluation of data}

Results of urinary ion excretion are expressed as deviation from the base line value, i.e., the mean of the two preceding control hours from 6 to 7 and from 7 to 8 a.m. Figures ( $\Delta$-change) are given in milliliters per minute. Student's $t$-test for paired observations was used for statistical analysis : the area of the mean $\Delta$-changes of experimental hours (from 8 a.m. to 1 p.m.) was calculated and the result was compared with the mean $\Delta$-changes on control day. The levels of statistical significance as well as the mean serum values and the $\Delta$-changes of $\mathrm{C}_{\mathrm{Cr}}$ are given in Tables II-VI.

\section{RESULTS}

In hypoparathyroid subjects, there was a marked increase in the mean value for the changes of $C_{P}$ (Fig. 1), $\mathrm{C}_{\mathrm{a}}, \mathrm{C}_{\mathrm{Mg}}$ (Fig. 2), $\mathrm{C}_{\mathrm{Na}}$ and $\mathrm{C}_{\mathrm{K}}$ (Fig. 3) during $\mathrm{CT}$ infusion when compared to those occurring during a $5 \%$ fructose infusion alone. The pooled CT data are highly significant for $\mathrm{P}, \mathrm{Ca}$, and $\mathrm{Mg}$ (Tables II-IV) and still significant for $\mathrm{Na}$ and $\mathrm{K}$ (Tables V, VI). Apparently, circadian variation did not influence these results (see controls). Between various CT peptides there was no significant difference of $\Delta$-changes (Fig.
4), in particular, human CT induced the same degree of phosphaturia, calciuria, and natriuresis as the porcine preparations. Only the two patients given salmon $\mathrm{CT}$, in MRC $\mathrm{U}$ equivalent doses, reacted with a somewhat more pronounced $\mathrm{P}, \mathrm{Ca}$, and $\mathrm{Na}$ excretion. However, the response of individual subjects to the different CT's varied more than the mean $\Delta$-changes. This finding, and the small number of experiments done with each preparation, precludes assessment of the relative potency of the various CT's.

PTE produced the well known increase of $C_{P}$ in all subjects, changes being significantly greater than with CT. Simultaneously, there was an increment of $\mathrm{C}_{\mathrm{Na}}$ and $\mathrm{C}_{\mathbf{K}}$; the sodium figure was not statistically significant. $\mathrm{C}_{\mathrm{Mg}}$ decreased significantly and $\mathrm{C}_{\mathrm{a}}$ insignificantly.

Neither the CT nor the PTE effects can be attributed to changes of the GFR. While urinary electrolytes were rising, $\mathrm{C}_{\mathrm{Cr}}$ remained stable or tended to fall (Fig. 1). However, deviations from the zero line are not statistically significant (Table II). Similarly, the changes of serum electrolytes were too small to explain the changes of the clearance figures. Even the largest difference between the initial and the final serum $\mathrm{P}$ with PTE was not statistically significant (Table II). 
TABLE III

Changes of Calcium Excretion ( $\Delta C_{C_{a}} / C_{C r} \mathrm{ml} / \mathrm{min}$ ) (including Serum-Ca mg/100 ml)

\begin{tabular}{|c|c|c|c|c|c|}
\hline \multirow[b]{2}{*}{ Time } & \multicolumn{3}{|c|}{ Hormone infusion } & \multirow[b]{2}{*}{11 a.m.-12 noon } & \multirow[b]{2}{*}{12 noon-1 p.m. } \\
\hline & 8-9 a.m. & 9-10 a.m. & 10-11 a.m. & & \\
\hline $\begin{array}{l}\text { Control } \\
\quad \text { Mean } \Delta \mathrm{C}_{\mathrm{Ca}} \\
\quad \pm \mathrm{SE}\end{array}$ & $\begin{array}{l}+0.10 \\
\pm 0.23\end{array}$ & $\begin{array}{l}-0.10 \\
\pm 0.07\end{array}$ & $\begin{array}{l}+0.02 \\
\pm 0.20\end{array}$ & $\begin{array}{l}-0.16 \\
\pm 0.26\end{array}$ & $\begin{array}{l}-0.36 \\
\pm 0.28\end{array}$ \\
\hline $\begin{array}{l}\text { Mean serum-Ca } \\
\pm \mathrm{SE}\end{array}$ & $\begin{array}{r}7.71 \\
\pm 0.35\end{array}$ & $\begin{array}{r}7.63 \\
\pm 0.32\end{array}$ & $\begin{array}{r}7.56 \\
\pm 0.32\end{array}$ & $\begin{array}{r}7.52 \\
\pm 0.35\end{array}$ & $\begin{array}{r}7.56 \\
\pm 0.33\end{array}$ \\
\hline $\begin{array}{l}\text { Calcitonin }(\mathrm{CT}) \\
\text { a. CT porcine extract } \\
\text { Mean } \Delta \mathrm{C}_{\mathrm{Ca}} \\
\text { 土SE } \\
\quad P(\text { compared with } b, c)\end{array}$ & $\begin{array}{l}+0.99 \\
\pm 0.46\end{array}$ & $\begin{array}{l}+0.82 \\
\pm 0.35\end{array}$ & $\begin{array}{l}+1.10 \\
\pm 0.31\end{array}$ & $\begin{array}{l}+1.06 \\
\pm 0.73\end{array}$ & $\begin{array}{l}+0.35 \\
\pm 0.19\end{array}$ \\
\hline $\begin{array}{l}\text { b. CT porcine synth. } \\
\text { Mean } \Delta \mathrm{C}_{\mathrm{C}} \\
\pm \mathrm{SE} \\
\quad P(\text { compared with } a, c)\end{array}$ & $\begin{array}{l}+0.79 \\
\pm 0.20\end{array}$ & $\begin{array}{l}+1.43 \\
\pm 0.44\end{array}$ & $\begin{array}{l}+1.69 \\
\pm 0.60\end{array}$ & $\begin{array}{l}+0.66 \\
\pm 0.32\end{array}$ & $\begin{array}{l}-0.17 \\
\pm 0.11\end{array}$ \\
\hline $\begin{array}{l}\text { c. CT human synth. } \\
\text { Mean } \Delta \mathrm{C}_{\mathrm{Ca}} \\
\pm \mathrm{SE} \\
\quad P \text { (compared with } a, b)\end{array}$ & $\begin{array}{l}+1.52 \\
\pm 0.78\end{array}$ & $\begin{array}{l}+2.06 \\
\pm 0.73\end{array}$ & $\begin{array}{l}+1.26 \\
\pm 0.43\end{array}$ & $\begin{array}{l}+0.59 \\
\pm 0.48\end{array}$ & $\begin{array}{l}-0.04 \\
\pm 0.18\end{array}$ \\
\hline $\begin{array}{l}\text { d. CT salmon synth. } \\
\text { Mean } \Delta \mathrm{C}_{\mathrm{Ca}} \\
\pm \mathrm{SE}\end{array}$ & $\begin{array}{l}+2.17 \\
\pm 0.27\end{array}$ & $\begin{array}{l}+4.69 \\
\pm 1.12\end{array}$ & $\begin{array}{l}+3.50 \\
\pm 0.19\end{array}$ & $\begin{array}{l}+2.73 \\
\pm 0.11\end{array}$ & $\begin{array}{l}+2.36 \\
\pm 0.42\end{array}$ \\
\hline $\begin{array}{l}\text { e. CT all studies } \\
\text { Mean } \Delta \mathrm{C}_{\mathrm{Ca}} \\
\quad \pm \mathrm{SE} \\
\quad P \text { (compared with control) }\end{array}$ & $\begin{array}{l}+1.25 \\
\pm 0.28\end{array}$ & $\begin{array}{l}+1.90 \\
\pm 0.43\end{array}$ & $\begin{array}{l}+1.66 \\
\pm 0.30\end{array}$ & $<0.001$ & $\begin{array}{l}+0.37 \\
\pm 0.25\end{array}$ \\
\hline $\begin{array}{l}\text { Mean serum-Ca } \\
\pm \mathrm{SE}\end{array}$ & $\begin{array}{r}6.67 \\
\pm 0.40\end{array}$ & $\begin{array}{r}6.68 \\
\pm 0.39\end{array}$ & $\begin{array}{r}6.66 \\
\pm 0.42\end{array}$ & $\begin{array}{r}6.51 \\
\pm 0.43\end{array}$ & $\begin{array}{r}6.46 \\
\pm 0.42\end{array}$ \\
\hline $\begin{array}{l}\text { PTE } \\
\text { Mean } \Delta \mathrm{C}_{\mathrm{Ca}} \\
\quad \pm \mathrm{SE} \\
\quad P \text { (compared with control) }\end{array}$ & $\begin{array}{l}+0.12 \\
\pm 0.25\end{array}$ & $\begin{array}{l}-0.06 \\
\pm 0.35\end{array}$ & $\begin{array}{l}-0.46 \\
\pm 0.37\end{array}$ & $\begin{array}{l}-0.94 \\
\pm 0.42\end{array}$ & $\begin{array}{l}-1.28 \\
\pm 0.49\end{array}$ \\
\hline $\begin{array}{l}\text { Mean serum-Ca } \\
\pm \mathrm{SE}\end{array}$ & $\begin{array}{r}6.35 \\
\pm 0.30\end{array}$ & $\begin{array}{r}6.26 \\
\pm 0.29\end{array}$ & $\begin{array}{r}6.32 \\
\pm 0.34\end{array}$ & $\begin{array}{r}6.36 \\
\pm 0.31\end{array}$ & $\begin{array}{r}6.40 \\
\pm 0.38\end{array}$ \\
\hline $\begin{array}{l}\mathrm{CT}+\mathrm{PTE} \\
\text { Mean } \Delta \mathrm{C}_{\mathrm{Ca}} \\
\quad \pm \mathrm{SE}\end{array}$ & $\begin{array}{l}+0.79 \\
\pm 0.30\end{array}$ & $\begin{array}{l}+1.38 \\
\pm 0.69\end{array}$ & $\begin{array}{l}+0.79 \\
\pm 0.32\end{array}$ & $\begin{array}{l}-0.21 \\
\pm 0.64\end{array}$ & $\begin{array}{l}-0.45 \\
\pm 0.57\end{array}$ \\
\hline $\begin{array}{l}\text { Mean serum-Ca } \\
\pm \mathrm{SE}\end{array}$ & $\begin{array}{r}6.40 \\
\pm 0.28\end{array}$ & $\begin{array}{r}6.65 \\
\pm 0.34\end{array}$ & $\begin{array}{r}6.41 \\
\pm 0.28\end{array}$ & $\begin{array}{r}6.49 \\
\pm 0.33\end{array}$ & $\begin{array}{r}6.46 \\
\pm 0.31\end{array}$ \\
\hline $\begin{array}{l}\text { Testing summation of } \mathrm{CT} \text { and } \mathrm{PT} \\
\left.\Sigma \text { (mean } \Delta \mathrm{C}_{\mathrm{C}_{\mathrm{a}}} \text { on } \mathrm{CT}^{*}\right) \\
+ \text { mean } \Delta \mathrm{C}_{\mathrm{Ca}} \text { on PTE) } \\
\text { 土SE } \\
P \text { (compared with observed } \\
\left.\Delta \mathrm{C}_{\mathrm{C}} \text { on } \mathrm{CT}+\mathrm{PTE}\right)\end{array}$ & $\begin{array}{l}\text { fects } \\
+1.02 \\
\pm 0.52 \\
\text { NS }\end{array}$ & $\begin{array}{c}+0.81 \\
\pm 0.47 \\
\text { NS }\end{array}$ & $\begin{array}{l}+0.54 \\
\pm 0.47 \\
\text { NS }\end{array}$ & $\begin{array}{c}-0.16 \\
\pm 0.29 \\
N S\end{array}$ & $\begin{array}{c}-0.90 \\
\pm 0.37 \\
\\
\text { NS }\end{array}$ \\
\hline $\begin{array}{l}\mathrm{PO}_{4} \\
\quad \text { Mean } \Delta \mathrm{C}_{\mathrm{Ca}} \\
\quad \pm \mathrm{SE}\end{array}$ & $\begin{array}{l}-0.12 \\
\pm 0.03\end{array}$ & $\begin{array}{l}+0.14 \\
\pm 0.20\end{array}$ & $\begin{array}{l}-0.07 \\
\pm 0.31\end{array}$ & $\begin{array}{l}-0.35 \\
\pm 0.61\end{array}$ & $\begin{array}{l}-0.54 \\
\pm 0.53\end{array}$ \\
\hline Mean serum-Ca & 7.76 & 7.49 & 7.48 & 7.41 & 7.51 \\
\hline
\end{tabular}

* Results of first CT study of each subject receiving later PTE and CT + PTE. 
TABLE IV

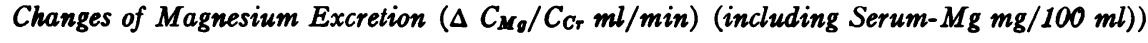

\begin{tabular}{|c|c|c|c|c|c|}
\hline \multirow[b]{2}{*}{ Time } & \multicolumn{3}{|c|}{ Hormone infusion } & \multirow[b]{2}{*}{11 a.m.-12 noon } & \multirow[b]{2}{*}{12 noon-1 p.m. } \\
\hline & 8-9 a.m. & 9-10 a.m. & 10-11 a.m. & & \\
\hline $\begin{array}{l}\text { Control } \\
\text { Mean } \Delta \mathrm{C}_{\mathbf{M}_{\mathbf{B}}} \\
\pm \mathrm{SE}\end{array}$ & $\begin{array}{l}+0.53 \\
\pm 0.41\end{array}$ & $\begin{array}{l}-0.52 \\
\pm 0.35\end{array}$ & $\begin{array}{l}-0.66 \\
\pm 0.36\end{array}$ & $\begin{array}{l}-1.11 \\
\pm 0.64\end{array}$ & $\begin{array}{l}-1.24 \\
\pm 0.84\end{array}$ \\
\hline $\begin{array}{l}\text { Mean serum-Mr } \\
\quad \text { ISE } \\
\text { Calcitonin (CT) }\end{array}$ & $\begin{array}{r}1.78 \\
\pm 0.05\end{array}$ & $\begin{array}{r}1.73 \\
\pm 0.06\end{array}$ & $\begin{array}{r}1.76 \\
\pm 0.04\end{array}$ & $\begin{array}{r}1.76 \\
\pm 0.05\end{array}$ & $\begin{array}{r}1.73 \\
\pm 0.05\end{array}$ \\
\hline $\begin{array}{l}\text { a. CT porcine extract } \\
\text { Mean } \Delta \mathrm{C}_{\mathrm{Mg}_{\mathrm{g}}} \\
\pm \mathrm{SE}\end{array}$ & $\begin{array}{l}+2.44 \\
\pm 0.97\end{array}$ & $\begin{array}{l}+1.67 \\
\pm 2.20\end{array}$ & $\begin{array}{l}+1.48 \\
\pm 1.90\end{array}$ & $\begin{array}{l}+0.58 \\
\pm 1.03\end{array}$ & $\begin{array}{l}-0.86 \\
\pm 1.08\end{array}$ \\
\hline $\begin{array}{l}\text { b. CT porcine synth. } \\
\text { Mean } \Delta \mathrm{C}_{\mathbf{M g}_{\mathrm{g}}} \\
\text { 土SE }\end{array}$ & $\begin{array}{l}+1.56 \\
\pm 1.48\end{array}$ & $\begin{array}{l}+2.37 \\
\pm 1.58\end{array}$ & $\begin{array}{l}+2.67 \\
\pm 1.57\end{array}$ & $\begin{array}{l}-0.13 \\
\pm 1.18\end{array}$ & $\begin{array}{l}-2.06 \\
\pm 0.83\end{array}$ \\
\hline $\begin{array}{l}\text { c. CT human synth. } \\
\text { Mean } \Delta \mathrm{C}_{\mathbf{M}_{\mathbf{g}}} \\
\pm \mathrm{SE}\end{array}$ & $\begin{array}{l}+3.33 \\
\pm 1.24\end{array}$ & $\begin{array}{l}+4.13 \\
\pm 1.70\end{array}$ & $\begin{array}{l}+2.83 \\
\pm 1.47\end{array}$ & $\begin{array}{l}+0.66 \\
\pm 1.60\end{array}$ & $\begin{array}{l}-0.15 \\
\pm 1.30\end{array}$ \\
\hline $\begin{array}{l}\text { d. CT salmon synth. } \\
\text { Mean } \Delta \mathrm{C}_{\mathrm{Mg}_{\mathrm{g}}} \\
\pm \mathrm{SE}\end{array}$ & $\begin{array}{l}+3.28 \\
\pm 3.06\end{array}$ & $\begin{array}{l}+4.29 \\
\pm 3.01\end{array}$ & $\begin{array}{l}+3.52 \\
\pm 3.01\end{array}$ & $\begin{array}{l}+1.24 \\
\pm 2.16\end{array}$ & $\begin{array}{l}-2.47 \\
\pm 0.48\end{array}$ \\
\hline $\begin{array}{l}\text { e. CT all studies } \\
\text { Mean } \Delta \mathrm{C}_{\mathrm{Mg}_{\mathrm{g}}} \\
\quad \pm \mathrm{SE} \\
\quad P \text { (compared with control) }\end{array}$ & $\begin{array}{l}+2.58 \\
\pm 0.68\end{array}$ & $\begin{array}{l}+2.95 \\
\pm 0.93\end{array}$ & $\begin{array}{l}+2.50 \\
\pm 0.82\end{array}$ & $\begin{array}{l}+0.46 \\
\pm 0.63\end{array}$ & $\begin{array}{l}-1.23 \\
\pm 0.55\end{array}$ \\
\hline $\begin{array}{l}\text { Serum-Mg } \\
\pm \mathrm{SE}\end{array}$ & $\begin{array}{r}1.67 \\
\pm 0.12\end{array}$ & $\begin{array}{r}1.60 \\
\pm 0.13\end{array}$ & $\begin{array}{r}1.56 \\
\pm 0.14\end{array}$ & $\begin{array}{r}1.52 \\
\pm 0.12\end{array}$ & $\begin{array}{r}1.51 \\
\pm 0.11\end{array}$ \\
\hline $\begin{array}{l}\text { PTE } \\
\text { Mean } \Delta \mathrm{C}_{\mathrm{Mg}_{\mathrm{g}}} \\
\quad \pm \mathrm{SE} \\
\quad P \text { (compared with control) }\end{array}$ & $\begin{array}{l}-0.87 \\
\pm 0.35\end{array}$ & $\begin{array}{l}-1.92 \\
\pm 0.72\end{array}$ & $\begin{array}{l}-2.92 \\
\pm 0.87\end{array}$ & $\begin{array}{l}-3.83 \\
\pm 0.95\end{array}$ & $\begin{array}{l}-3.06 \\
\pm 1.74\end{array}$ \\
\hline $\begin{array}{l}\text { Mean serum-Mg } \\
\pm \mathrm{SE}\end{array}$ & $\begin{array}{r}1.56 \\
\pm 0.12\end{array}$ & $\begin{array}{r}1.54 \\
\pm 0.13\end{array}$ & $\begin{array}{r}1.55 \\
\pm 0.11\end{array}$ & $\begin{array}{r}1.56 \\
\pm 0.12\end{array}$ & $\begin{array}{r}1.44 \\
\pm 0.10\end{array}$ \\
\hline $\begin{array}{l}\mathrm{CT}+\mathrm{PTE} \\
\text { Mean } \Delta \mathrm{C}_{\mathbf{M g}_{\mathrm{g}}} \\
\quad \pm \mathrm{SE}\end{array}$ & $\begin{array}{l}+1.23 \\
\pm 1.20\end{array}$ & $\begin{array}{l}+0.31 \\
\pm 2.14\end{array}$ & $\begin{array}{l}-1.30 \\
\pm 1.44\end{array}$ & $\begin{array}{l}-2.96 \\
\pm 1.10\end{array}$ & $\begin{array}{l}-5.04 \\
\pm 0.79\end{array}$ \\
\hline $\begin{array}{l}\text { Mean serum-Mg } \\
\pm \mathrm{SE}\end{array}$ & $\begin{array}{r}1.65 \\
\pm 0.12\end{array}$ & $\begin{array}{r}1.63 \\
\pm 0.14\end{array}$ & $\begin{array}{r}1.60 \\
\pm 0.13\end{array}$ & $\begin{array}{r}1.57 \\
\pm 0.13\end{array}$ & $\begin{array}{r}1.54 \\
\pm 0.14\end{array}$ \\
\hline $\begin{array}{l}\text { Testing summation of CT and } \mathrm{F} \\
\Sigma\left(\text { mean } \Delta \mathrm{C}_{\mathrm{Mg}_{\mathrm{g}}} \text { on } \mathrm{CT}^{*}\right. \\
+ \text { mean } \Delta \mathrm{C}_{\mathrm{Mg}_{\mathrm{g}}} \text { on PTE) } \\
\pm \mathrm{SE} \\
P \text { (compared with observed } \\
\left.\quad \Delta \mathrm{C}_{\mathbf{M g}_{\mathrm{g}}} \text { on } \mathrm{CT}+\mathrm{PTE}\right)\end{array}$ & $\begin{array}{l}+1.97 \\
\pm 1.06 \\
\text { NS }\end{array}$ & $\begin{array}{l}+0.82 \\
\pm 2.13\end{array}$ & $\begin{array}{l}-0.41 \\
\pm 2.23\end{array}$ & $\begin{array}{l}-3.08 \\
\pm 1.58\end{array}$ & $\begin{array}{c}-3.99 \\
\pm 2.13 \\
\\
\text { NS }\end{array}$ \\
\hline $\begin{array}{l}\mathrm{PO}_{4} \\
\quad \text { Mean } \Delta \mathrm{C}_{\mathrm{Mg}} \\
\quad \pm \mathrm{SE}\end{array}$ & $\begin{array}{l}+0.27 \\
\pm 0.82\end{array}$ & $\begin{array}{l}-0.06 \\
\pm 0.08\end{array}$ & $\begin{array}{l}+0.54 \\
\pm 1.33\end{array}$ & $\begin{array}{l}-0.65 \\
\pm 0.41\end{array}$ & $\begin{array}{l}+0.86 \\
\pm 1.86\end{array}$ \\
\hline Mean serum- $\mathrm{Mg}$ & 1.51 & 1.56 & 1.45 & 1.50 & 1.49 \\
\hline
\end{tabular}

* Results of first CT study of each subject receiving later PTE and CT + PTE. 
TABLE V

Changes of Sodium Excretion ( $\Delta C_{N a} / C_{C r} \mathrm{ml} / \mathrm{min}$ ) (including Serum-Na mEq/liter)

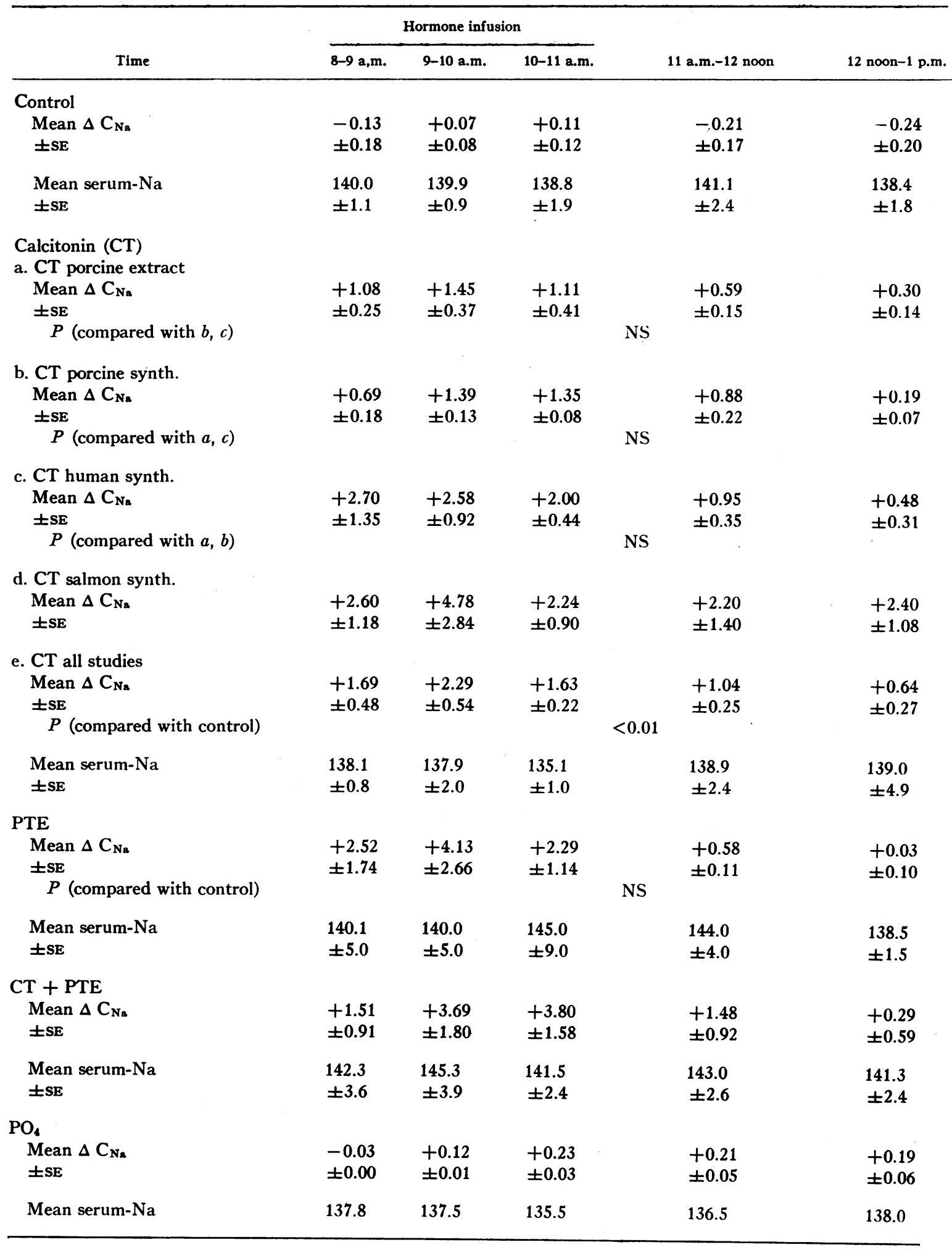


When CT was added to PTE, the changes of $C_{P}$, $\mathrm{C}_{\mathrm{Na}}$, and $\mathrm{C}_{\mathrm{K}}$ were not appreciably influenced, but the combination of the two hormones resulted in a summation of the individual effects on $\mathrm{Cc}_{\mathbf{a}}$ and $\mathrm{C}_{\mathbf{M}_{\mathrm{g}}}$. As demon- strated in Fig. 2, the calculated and the observed excretion pattern can nearly be superimposed; the differences are not statistically significant (Tables III, IV). The phosphate infusion produced a phosphaturia of

TABLE VI

Changes of Potassium Excretion ( $\Delta C_{K} / C_{C_{r}} \mathrm{ml} / \mathrm{min}$ ) (including Serum-K $m E q /$ liter)

\begin{tabular}{|c|c|c|c|c|c|}
\hline \multirow[b]{2}{*}{ Time } & \multicolumn{3}{|c|}{ Hormone infusion } & \multirow[b]{2}{*}{11 a.m.-12 noon } & \multirow[b]{2}{*}{12 noon-1 p.m. } \\
\hline & 8-9 a.m. & 9-10 a.m. & 10-11 a.m. & & \\
\hline \multicolumn{6}{|l|}{ Control } \\
\hline $\begin{array}{l}\text { Mean } \Delta \mathrm{C}_{\mathrm{K}} \\
\pm \mathrm{SE}\end{array}$ & $\begin{array}{l}-0.38 \\
\pm 1.16\end{array}$ & $\begin{array}{l}-1.70 \\
\pm 1.57\end{array}$ & $\begin{array}{l}-2.56 \\
\pm 1.59\end{array}$ & $\begin{array}{l}-4.11 \\
\pm 1.94\end{array}$ & $\begin{array}{l}-4.51 \\
\pm 2.36\end{array}$ \\
\hline $\begin{array}{l}\text { Mean serum-K } \\
\pm \text { SE }\end{array}$ & $\begin{array}{r}4.33 \\
\pm 0.12\end{array}$ & $\begin{array}{r}4.21 \\
\pm 0.15\end{array}$ & $\begin{array}{r}4.18 \\
\pm 0.21\end{array}$ & $\begin{array}{r}4.31 \\
\pm 0.19\end{array}$ & $\begin{array}{r}4.24 \\
\pm 0.18\end{array}$ \\
\hline \multicolumn{6}{|l|}{$\begin{array}{l}\text { Calcitonin (CT) } \\
\text { a. CT porcine extract }\end{array}$} \\
\hline $\begin{array}{l}\text { Mean } \Delta \mathrm{C}_{\mathbf{K}} \\
\pm \mathrm{SE}\end{array}$ & $\begin{array}{r}+14.19 \\
\pm 2.07\end{array}$ & $\begin{array}{r}+10.43 \\
\pm 2.02\end{array}$ & $\begin{array}{l}+8.23 \\
\pm 5.61\end{array}$ & $\begin{array}{l}+5.25 \\
\pm 3.38\end{array}$ & $\begin{array}{l}+2.70 \\
\pm 1.12\end{array}$ \\
\hline \multicolumn{6}{|l|}{ b. CT porcine synth. } \\
\hline $\begin{array}{l}\text { Mean } \Delta C_{K} \\
\pm S E\end{array}$ & $\begin{array}{r}+10.49 \\
\pm 9.11\end{array}$ & $\begin{array}{l}+17.22 \\
\pm 10.86\end{array}$ & $\begin{array}{r}+10.26 \\
\pm 3.04\end{array}$ & $\begin{array}{l}+4.08 \\
\pm 1.02\end{array}$ & $\begin{array}{l}+5.78 \\
\pm 0.83\end{array}$ \\
\hline \multicolumn{6}{|l|}{ c. CT human synth. } \\
\hline $\begin{array}{l}\text { Mean } \Delta C_{K} \\
\pm S E\end{array}$ & $\begin{array}{l}+28.49 \\
\pm 22.04\end{array}$ & $\begin{array}{l}+28.95 \\
\pm 20.96\end{array}$ & $\begin{array}{r}+17.97 \\
\pm 9.30\end{array}$ & $\begin{array}{r}+12.00 \\
\pm 4.51\end{array}$ & $\begin{array}{l}+7.52 \\
\pm 1.73\end{array}$ \\
\hline \multicolumn{6}{|l|}{ d. CT salmon synth. } \\
\hline $\begin{array}{l}\text { Mean } \Delta \mathrm{C}_{\mathrm{K}} \\
\pm \mathrm{SE}\end{array}$ & $\begin{array}{r}+12.03 \\
\pm 6.49\end{array}$ & $\begin{array}{r}+17.30 \\
\pm 9.16\end{array}$ & $\begin{array}{r}+10.48 \\
\pm 4.38\end{array}$ & $\begin{array}{r}+12.40 \\
\pm 7.14\end{array}$ & $\begin{array}{r}+12.70 \\
\pm 9.06\end{array}$ \\
\hline \multicolumn{6}{|l|}{ e. CT all studies } \\
\hline $\begin{array}{l}\text { Mean } \Delta \mathrm{C}_{\mathrm{K}} \\
\quad \pm \mathrm{SE} \\
\quad P(\text { compared with control) }\end{array}$ & $\begin{array}{r}+17.12 \\
\pm 7.03\end{array}$ & $\begin{array}{r}+19.27 \\
\pm 6.94\end{array}$ & $\begin{array}{r}+12.27 \\
\pm 3.17\end{array}$ & $\begin{array}{l}+8.07 \\
\pm 1.98\end{array}$ & $\begin{array}{l}+6.67 \\
\pm 1.48\end{array}$ \\
\hline $\begin{array}{l}\text { Mean serum-K } \\
\pm \mathrm{SE}\end{array}$ & $\begin{array}{r}4.07 \\
\pm 0.15\end{array}$ & $\begin{array}{r}3.99 \\
\pm 0.13\end{array}$ & $\begin{array}{r}4.15 \\
\pm 0.18\end{array}$ & $\begin{array}{r}3.77 \\
\pm 0.13\end{array}$ & $\begin{array}{r}3.50 \\
\pm 0.10\end{array}$ \\
\hline \multicolumn{6}{|l|}{ PTE } \\
\hline $\begin{array}{l}\text { Mean } \Delta \mathrm{C}_{\mathrm{K}} \\
\pm \mathrm{SE} \\
\quad P \text { (compared with control) }\end{array}$ & $\begin{array}{r}+13.90 \\
\pm 4.80\end{array}$ & $\begin{array}{r}+27.65 \\
\pm 8.12\end{array}$ & $\begin{array}{r}+19.22 \\
\pm 4.38\end{array}$ & $\begin{array}{r}+11.79 \\
\pm 3.00\end{array}$ & $\begin{array}{l}+1.90 \\
\pm 3.28\end{array}$ \\
\hline $\begin{array}{l}\text { Mean serum-K } \\
\pm \mathrm{SE}\end{array}$ & $\begin{array}{r}3.96 \\
\pm 0.45\end{array}$ & $\begin{array}{r}3.98 \\
\pm 0.25\end{array}$ & $\begin{array}{r}4.43 \\
\pm 0.58\end{array}$ & $\begin{array}{r}4.22 \\
\pm 0.52\end{array}$ & $\begin{array}{r}4.58 \\
\pm 0.18\end{array}$ \\
\hline $\begin{array}{l}\mathrm{CT}+\mathrm{PTE} \\
\quad \text { Mean } \Delta \mathrm{C}_{\mathrm{K}} \\
\quad \pm \mathrm{SE}\end{array}$ & $\begin{array}{r}+20.35 \\
\pm 9.69\end{array}$ & $\begin{array}{l}+37.63 \\
\pm 21.45\end{array}$ & $\begin{array}{l}+46.00 \\
\pm 20.18\end{array}$ & $\begin{array}{r}+16.96 \\
\pm 7.14\end{array}$ & $\begin{array}{l}+1.32 \\
\pm 3.10\end{array}$ \\
\hline $\begin{array}{l}\text { Mean serum-K } \\
\pm \mathrm{SE}\end{array}$ & $\begin{array}{r}4.30 \\
\pm 0.32\end{array}$ & $\begin{array}{r}4.22 \\
\pm 0.11\end{array}$ & $\begin{array}{r}4.18 \\
\pm 0.15\end{array}$ & $\begin{array}{r}4.17 \\
\pm 0.42\end{array}$ & $\begin{array}{r}4.33 \\
\pm 0.35\end{array}$ \\
\hline $\begin{array}{l}\mathrm{PO}_{4} \\
\quad \text { Mean } \Delta \mathrm{C}_{\mathrm{K}} \\
\quad \pm \mathrm{SE}\end{array}$ & $\begin{array}{l}-0.34 \\
\pm 0.26\end{array}$ & $\begin{array}{l}-0.51 \\
\pm 0.42\end{array}$ & $\begin{array}{l}+0.91 \\
\pm 1.00\end{array}$ & $\begin{array}{l}+1.88 \\
\pm 0.70\end{array}$ & $\begin{array}{l}+1.97 \\
\pm 2.55\end{array}$ \\
\hline Mean serum-K & 4.38 & 3.70 & 3.75 & 3.70 & 3.50 \\
\hline
\end{tabular}



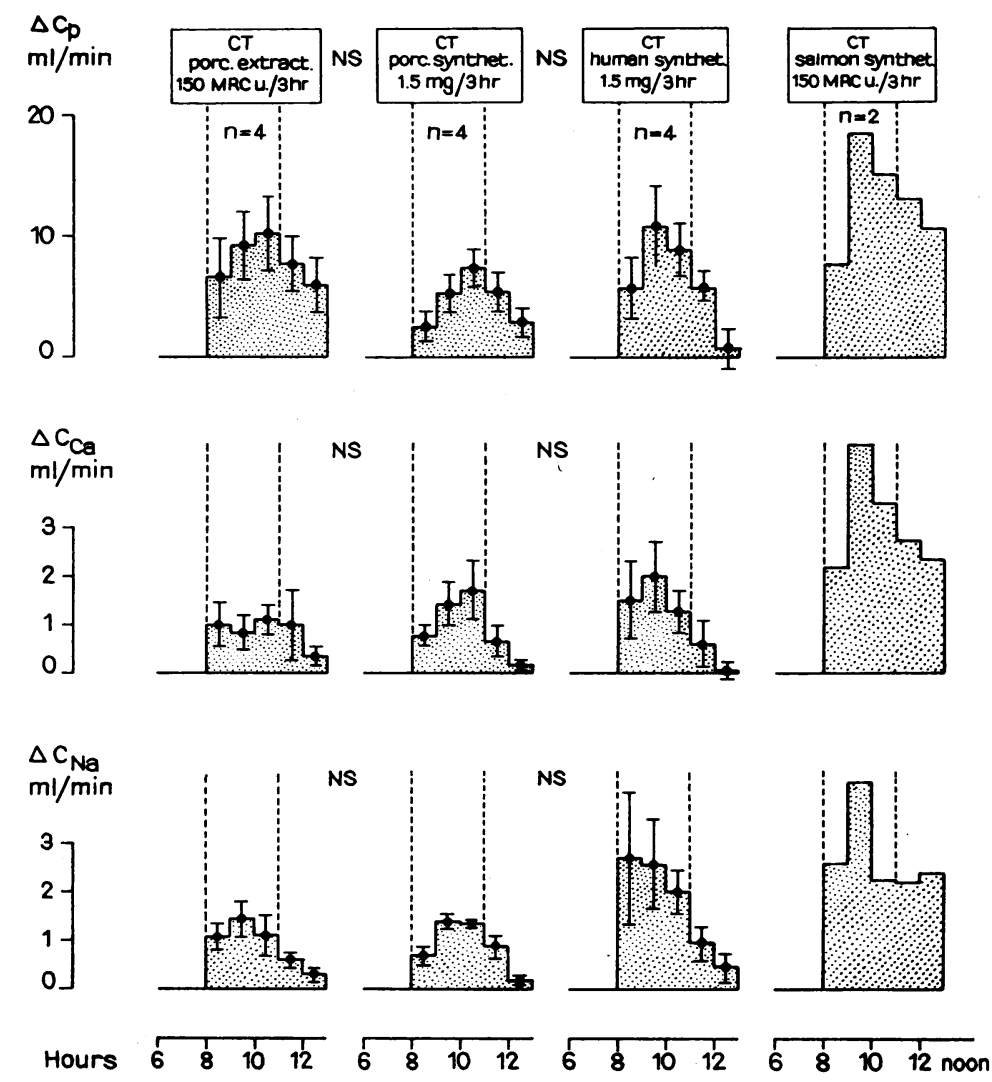

Figure 4 Differential effects of various calcitonins on $C_{P}$ (top), $C_{0 a}$ (middle), and $\mathrm{C}_{\mathrm{Na}}$ (bottom). Differences between individual CT effects are statistically not significant.

similar degree as seen after salmon CT in the two subjects tested (Fig. 5). This type of phosphaturia however was not accompanied by any significant change of cation excretion. Increasing the serum $\mathrm{P}$ by phosphate infusion did not significantly influence the level of serum cations. Furthermore, no major blood $\mathrm{pH}$ changes were observed in the one subject tested (S. E.) : corresponding values before and after $\mathrm{P}$ infusion were $\mathrm{pH} 7.41$ and 7.38; standard bicarbonate 25.3 and $23.2 \mathrm{mEq} /$ liter. The cation excretion patterns of hormonal and nonhormonal phosphaturia are so different that there remain little doubts about a direct influence of $\mathrm{CT}$ on renal $\mathrm{Ca}, \mathrm{Mg}, \mathrm{Na}$, and $\mathrm{K}$ excretion.

\section{DISCUSSION}

The present studies document that pharmacologic doses of $\mathrm{CT}$ increase the renal clearance of $\mathrm{P}, \mathrm{Na}, \mathrm{K}, \mathrm{Ca}$, and $\mathrm{Mg}$ in hypoparathyroid human patients. This effect, as well as the observed response to PTE, cannot satisfactorily be explained on the basis of an altered filtered load of these ions. While the urinary electrolytes were rising, $\mathrm{C}_{\mathrm{cr}}$ remained stable or tended to fall. This find- ing rules out a significant hemodynamic effect of PTE on GFR such as has been reported in dogs (30). Similarly, serum electrolytes did not show a significant variation. Therefore, CT appears to exert direct renal effects. Interestingly enough, this kidney response seems to be species dependent: in the PTX dog porcine CT does not produce phosphaturia $(6,8)$ which was seen in all our hypoparathyroid subjects. All CT's including the human peptide provoked this response. As demonstrated also by direct injection of CT into one renal artery (31), this effect is not mediated through the parathyroids in man. If this phenomenon, observed after pharmacologic doses, has physiologic significance (see below), CT may play an important role in the maintenance of $\mathrm{P}$ homeostasis, to some extent in concert with PTH. The plasma Ca lowering CT effect is proportional to the starting $\mathrm{P}$ level (32), and in dogs, the $\mathrm{P}$ depressing effect is more prominent (33). Jowsey and Detenbeck (25) have shown that in a state of CT deficiency $\mathrm{P}$ is stored in soft tissues. After administration of the hormone this $\mathrm{P}$ is released immediately into the ECF, with a consequent initial rise of plasma $P$. 


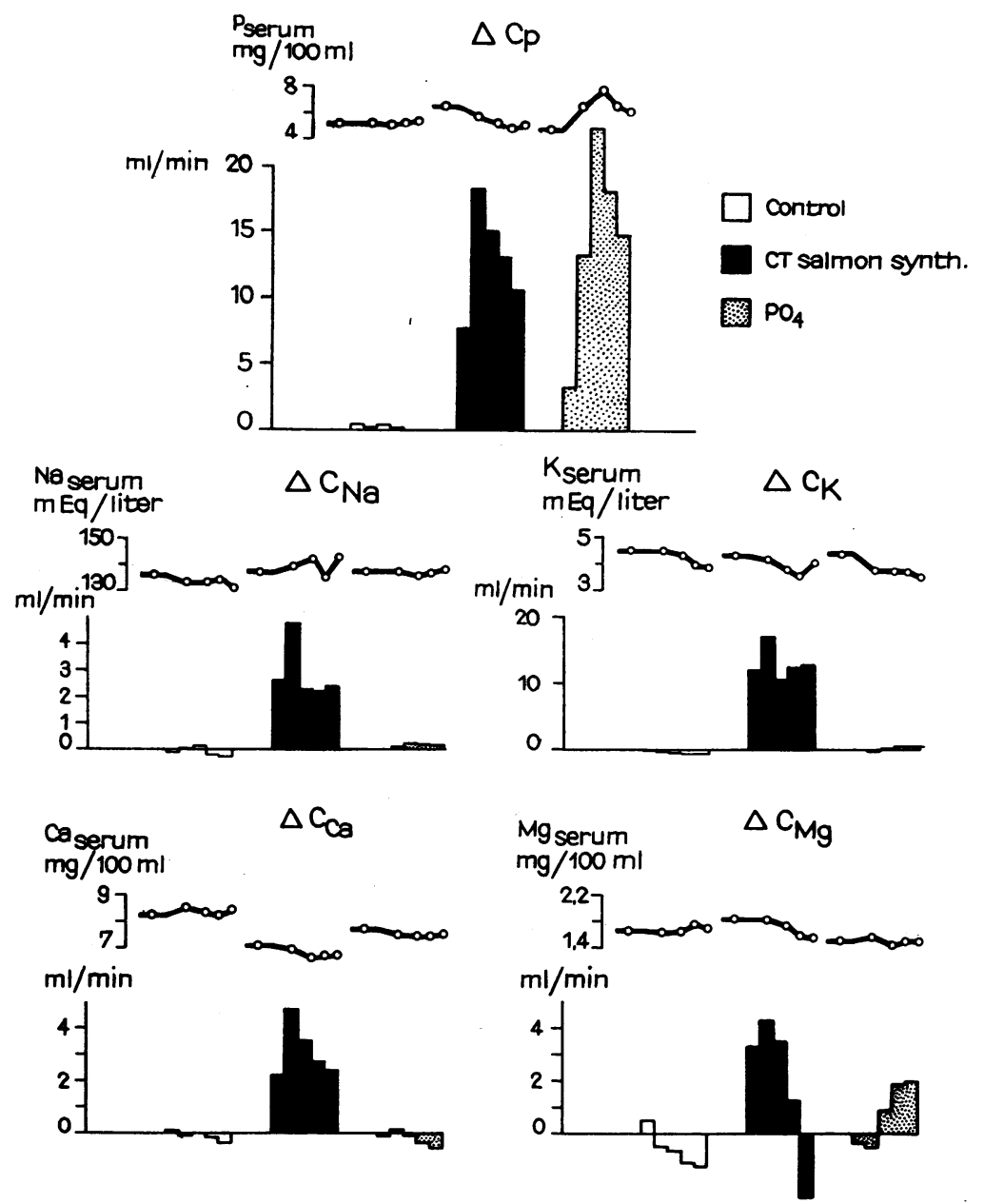

FIGURE 5 Influence of hormonal and nonhormonal phosphaturia on cation excretion. Note that $\mathrm{PO}_{4}$-infusion as $\left(\mathrm{NH}_{4}\right)_{2} \mathrm{HPO}_{4}$ caused minimal and insignificant changes in $\Delta \mathrm{C}_{\mathrm{Na}}, \Delta \mathrm{C}_{\mathrm{K}}, \Delta \mathrm{C}_{\mathrm{C} \mathbf{a}}$, and $\Delta \mathrm{C}_{\mathrm{Mg}}$.

These data suggest that CT may act to prevent soft tissue accumulation of phosphate.

In our patients, both PTE and CT produced a phosphaturic response of the same duration. This finding has some bearing on the argument whether $\mathrm{P}$ excretion is of use in establishing the diagnosis of primary hyperparathyroidism. Robinson, Martin, and McIntyre (3) suggested that $P$ excretion indices should not be used for diagnostic purposes because CT was accused of interfering with renal $\mathrm{P}$ handling. If the CT-dependent phosphaturia is significant, $C_{P}$ should increase or remain unchanged following a $\mathrm{Ca}$ infusion. Not only would this suppress the parathyroids but at the same time stimulate CT secretion (1). Since in normal subjects, $C_{P}$ drops significantly (34), PTH appears to dominate $C_{\mathbf{r}}$. Thus, Robinson's theoretical objection does not invalidate the "parathyroid suppression test" for diagnostic purposes.
In a close temporal relationship to the change of $\mathrm{P}$ excretion, all CT peptides produced a significant increase of $C_{\mathbf{N a}}$ and $C_{\mathbf{k}}$. The natriuretic effect seems to be a regular finding both in experimental animals (4), in normal subjects, and in patients with metabolic bone disease $(10-12,35)$. That we are dealing with a true hormonal effect was shown in the two patients given an ammonium phosphate infusion: the same degree of phosphaturia was obtained without significant changes of blood $\mathrm{pH}$ and serum cations, but the $C_{P}$ peak was not associated with a relevant increase of cation excretion (Fig. 5). Prolonged administration of CT, which in our short-term experiments acted as a diuretic, may therefore be responsible for sodium and water loss recently observed in two CT-treated osteoporotic patients (36).

All CT peptides produced an increase of $\mathrm{Cc}_{\mathbf{a}}$ and $\mathrm{C}_{\mathbf{M g}}$ in our patients and the combined administration of CT 
and PTE resulted in a summation of individual hormone effects (Fig. 2). These results were obtained with pharmacologic doses of CT and PTE, but Ardaillou et al. (13) reported a significant increase of $\mathrm{UCa}$ in human subjects who were given an infusion with only $0.4 \mathrm{MRC} U$ porcine $\mathrm{CT} / \mathrm{hr}$. This figure approaches measured hormone quantities secreted in the pig (37). Hence, our data might have physiological significance. They are at variance with the data of Rasmussen, Anast, and Arnaud (4) who found a reduction of $\mathrm{UCa}$ and $\mathrm{UMg}$ in young rats given $\mathrm{CT}$. The likely explanation for this discrepancy lies with the state of bone remodeling. In the growing animal, the CT bone effect prevails over the kidney response which in turn becomes more prominent in a state of low bone turnover (38) such as in mature adults and hypoparathyroidism $(39,40)$. Our data tend to support the original concept of Copp, Cameron, Cheney, Davidson, and Henze (41) who postulated that CT acts as a regulator of $\mathrm{Ca}$ homeostasis in concert with PTH. Earlier, we have reported experiments in man suggesting that only a limited fraction of extracellular $\mathrm{Ca}$ is available for CT action (42). The immediate and transitory fall of serum $\mathrm{Ca}$ after $\mathrm{CT}$ can best be explained by influences on the incorporation of $\mathrm{Ca}$ into a labile bone pool (43) and/or on the renal Ca transport. The renal $\mathrm{Ca}$ effect of $\mathrm{CT}$ becomes even more important if one considers the recently appreciated prominent role the kidney seems to play in $\mathrm{Ca}$ homeostasis (44). Hence, PTH and CT appear to be true antagonists: PTH increases blood $\mathrm{Ca}$ by facilitating intestinal and tubular transport and mobilizing $\mathrm{Ca}$ from the bone. $\mathrm{CT}$ on the other hand works in opposition by accelerating $\mathrm{Ca}$ entry into bone and enhancing renal $\mathrm{Ca}$ elimination. $\mathrm{CT}$ would then be of therapeutic use only in conditions resembling the growth period, i.e., states with high bone turnover, such as Paget's disease (36). In situations with low bone turnover, e.g., senile osteoporosis, prolonged CT administration may lead to a progressive $\mathrm{Ca}$ loss already reported in two osteoporotic subjects (36). It seems doubtful that even the minimal CT doses proposed for the long-term treatment of osteoporosis $(13,31)$ are low enough to protect the bone from $\mathrm{Ca}$ depletion without inducing renal $\mathrm{Ca}$ loss. However, one should keep in mind that acute effects, such as reported in this paper, do not necessarily apply to prolonged administration of CT.

\section{ACKNOWLEDGMENTS}

We are indebted to Ciba Pharmaceutical Co., Basel and Sandoz AG Basel for the generous gifts of calcitonins. The advice and critique of Doctors G. Thiel, F. Bühler, F. Brunner, and J. Pryor were of great help. Furthermore, we wish to express our gratitude to Dr. H. Bartels and Prof. H. Reber, Division of Chemical Pathology, and to Miss
U. Brand, Y. Dorvé, K. Henriksen, R. Merz, M. Walser, E. Schori, and P. R. Sandifer for skillful assistance.

This work was supported by grants 4121 and 3.104 .69 of the Schweizerischer Nationalfonds zur Förderung der wissenschaftlichen Forschung as well as a research grant from Ciba Basel.

\section{REFERENCES}

1. Hirsch, P. F., and P. L. Munson. 1969. Thyrocalcitonin. Physiol. Rev. 49: 548.

2. Kenny, A. D., and C. A. Heiskell. 1965. Effect of crude thyrocalcitonin on calcium and phosphorus metabolism in rats. Proc. Soc. Exp. Biol. Med. 120: 269.

3. Robinson, C. J., T. J. Martin, and I. MacIntyre. 1966. Phosphaturic effect of thyrocalcitonin. Lancet. 2: 83.

4. Rasmussen, H., C. Anast, and C. Arnaud. 1967. Thyrocalcitonin, EGTA and urinary electrolyte excretion. $J$. Clin. Invest. 46: 746.

5. Ziegler, R., B. Lemmer, and E. F. Pfeiffer. 1967. Ueber die Einwirkung von Thyreocalcitonin auf die Phosphaturie. Klin. Wochenschr. 45: 34.

6. Clark, J. D., and A. D. Kenny. 1969. Hog thyrocalcitonin in the dog: urinary calcium, phosphorus, magnesium and sodium responses. Endocrinology. 84: 1199.

7. Cramer, C. F., C. O. Parkes, and D. H. Copp. 1969. The effect of chicken and hog calcitonin on some parameters of $\mathrm{Ca}, \mathrm{P}$ and $\mathrm{Mg}$ metabolism in dogs. Can. J. Physiol. Pharmacol. 47: 181.

8. Pak, C. Y. C., B. Ruskin, and A. Casper. 1970. Renal effects of porcine thyrocalcitonin in the dog. Endocrinology. $87: 262$.

9. Russell, R. G. G., and H. Fleisch. 1968. The renal effects of thyrocalcitonin in the pig and dog. In Calcitonin: Proceedings of the Symposium on Thyrocalcitonin and the C cells. S. Taylor, editor. William Heinemann, Ltd., London. 297.

10. Bijvoet, O. L. M., J. Van der Sluys Veer, and A. P. Jansen. 1968. Effects of calcitonin on patients with Paget's disease, thyrotoxicosis or hypercalcaemia. Lancet. 1: 876.

11. Martin, T. J., and R. A. Melick. 1969. The acute effects of porcine calcitonin in man. Australas. Ann. Med. 18: 258.

12. Cochran, M., M. Peacock, G. Sachs, and B. E. C. Nordin. 1970. Renal effects of calcitonin. Brit. Med. J. 1: 135.

13. Ardaillou, R., J. P. Fillastre, G. Milhaud, F. Rousselet, F. Delaunay, and G. Richet. 1969. Renal excretion of phosphate, calcium and sodium during and after a prolonged thyrocalcitonin infusion in man. Proc. Soc. Exp. Biol. Med. 131: 56.

14. Dambacher, M. A., and H. G. Haas. 1969. Untersuchungen über die phosphaturische Wirkung von Calcitonin und Parathormon beim Menschen. Symp. Deut. Ges. Endokrinol. 15: 406 (Abstr.)

15. Dambacher, M. A., J. Guncaga. T. Lauffenburger, and H. G. Haas. 1970. Kalzitoninwirkungen auf die Niere des Menschen. Schweiz. Med. Wochensch. 100: 548 (Abstr.)

16. Eisenberg, E. 1968. Renal effects of parathyroid hormone. In Parathyroid Hormone and Thyrocalcitonin (Calcitonin). R. V. Talmage, L. F. Bélanger, I. Clark, editors. Excerpta Medica Foundation, Publishers, Amsterdam. 465. 
17. Burkhart, J. M., and J. Jowsey. 1966. Morphologic evidence of osteomalacia in the parathyroidectomized dog. Mayo Clin. Proc. 41: 663.

18. Steele, T. H. 1970. Increased urinary phosphate excretion following volume expansion in normal man. $M e-$ tab. Clin. Exp. 19: 129.

19. Hellman, D. E., W. Y. W. Au, and F. C. Bartter. 1964. Evidence for a direct effect of parathyroid hormone on urinary acidification. Amer. J. Physiol. 209: 643.

20. Kleeman, C. R., S. Ling, D. Bernstein, M. H. Maxwell, and L. Chapman. 1966. The effect of independent changes in glomerular filtration (GFR) and sodium $(\mathrm{Na}+)$ excretion on the renal excretion of calcium $(\mathrm{Ca}++)$ and magnesium $(\mathrm{Mg}++)$ in acutely hypercalcemic dogs. J. Clin. Invest. 45: 1032. (Abstr.)

21. Kahnt, F. W., B. Riniker, I. MacIntyre, and R. Neher. 1968. Thyrocalcitonin. I. Isolierung und Charakterisierung wirksamer Peptide aus Schweineschilddrüsen. Helv. Chim. Acta. 51: 214.

22. Rittel, W., M. Brugger, B. Kamber, B. Riniker, and P. Sieber. 1968. Thyrocalcitonin. III. Die Synthese des $\alpha$ Thyrocalcitonins. Helv. Chim. Acta. 51: 924.

23. Sieber, P., M. Brugger, B. Kamber, B. Riniker, and W. Rittel. 1968. Menschliches Calcitonin. IV. Die Synthese von Calcitonin M. Helv. Chim. Acta. 51: 2057.

24. Guttmann, S., J. Pless, R. L. Huguenin, E. Sandrin, H. Bossert, and K. Zehnder. 1969. Synthese von SalmCalcitonin, einem hochaktiven hypocalcämischen Hormon. Helv. Chim. Acta. 52: 1789.

25. Jowsey, J., and L. C. Detenbeck. 1969. Importance of thyroid hormones in bone metabolism and calcium homeostasis. Endocrinology. 85: 87.

26. Toribara, T. Y., A. R. Terepka, and P. A. Dewey. 1957. The ultrafiltrable calcium of human serum. I. Ultrafiltration methods and normal values. J. Clin. Invest. 36: 738.

27. MacIntyre, I. 1961. Flame photometry. Advan. Clin. Chem. 4: 1 .

28. Fiske, C. H., and Y. Subbarow. 1925. The colorimetric determination of phosphorus. J. Biol. Chem. 66: 375.

29. Clark, L. C., Jr., and H. L. Thompson. 1949. Determination of creatine and creatinine in urin. Anal. Chem. $21: 1218$.

30. Charbon, G. A., and E. E. M. Pieper. 1970. Influence of calcitonin on parathyroid hormone-induced augmentations of arterial hepatic and renal flow. In International Symposium on Calcitonin, 2nd, London, 1969. Calcitonin 1969. Proceedings. S. Taylor and G. Foster, editors. Springer Publishing Co., Inc., New York. 451.
31. Milhaud, G., M. S. Moukhtar, A. M. Perault-Staub, G. Coutris, R. Ardaillou, H. Bloch-Michel, J. M. Garel, E. Klingler, M. Tubiana, and P. C. Sizonenko. 1970. Studies in thyrocalcitonin. In International Symposium on Calcitonin, 2nd, London, 1969. Calcitonin 1969. Proceedings. S. Taylor and G. Foster, editors. Springer Publishing Co., Inc., New York. 182.

32. Kennedy, J. W., F. S. Tanzer, and R. V. Talmage. 1969. Plasma phosphate and the hypocalcemic response of intact, parathyroidectomized and nephrectomized rats to thyrocalcitonin. Endocrinology. 85: 657.

33. Jowsey, J. 1969. Serum calcium and phosphate changes in thyroidectomized dogs. Calcified Tissue Res. 4: 188.

34. Haas, H. G. 1966. Metabolic criteria for primary hyperparathyroidism. Helv. Med. Acta. 33: 91.

35. Shai, F., R. K. Baker, and S. Wallach. 1970. Metabolic and clinical efficacy of calcitonin in Paget's disease. J. Clin. Invest. $49: 87$ a. (Abstr. 277.)

36. Bijvoet, O. L. M., J. van der Sluys Veer, J. Wildiers, and D. Smeenk. 1970. Effects of long term calcitonin administration to patients. In International Symposium on Calcitonin, 2nd, London, 1969. Calcitonin 1969. Proceedings. S. Taylor and G. Foster, editors. Springer Publishing Co., Inc., New York. 531.

37. Care, A. D., P. F. L. Bates, and H. J. Gitelman. 1970. A possible role for the adenyl cyclase system in calcitonin release. J. Endocrinol. 48: 1.

38. Robinson, C. J., T. J. Martin, E. W. Matthews, and I. MacIntyre. 1967. Mode of action of thyrocalcitonin. J. Endocrinol. 39: 71 .

39. Haas, H. G., A. J. Olah, and M. Dambacher. 1968. Hypoparathyreoidismus. Deut. Med. Wochenschr. 93: 1383.

40. Litvak, J., E. Oberhauser, J. Riesco, O. Lopez, R. Armendaris, I. Alliende, and F. Solis. 1967. Strontium85 kinetics in hypoparathyroidism at different levels of calcium intake. J. Nucl. Med. 8: 60 .

41. Copp, D. H., E. C. Cameron, B. A. Cheney, A. G. F. Davidson, and K. G. Henze. 1962. Evidence for calcitonin-a new hormone from the parathyroid that lowers blood calcium. Endocrinology. 70: 638.

42. Haas, H. G., and M. A. Dambacher, 1968. Thyrocalcitonin effects in man. Helv. Med. Acta. 34: 327.

43. Haas, H. G., M. Dambacher, R. K. Schenk, and A. J. Olah. 1968. Mode of thyrocalcitonin action in man. Calcified Tissue Res. 2(Suppl.) : 21. (Abstr.)

44. Peacock, M., W. G. Robertson, B. E. C. Nordin. 1969. Relation between serum and urinary calcium with particular reference to parathyroid activity. Lancet. 1: 384. 